\title{
Rapid Metaphase and Interphase Detection of Radiation-Induced Chromosome Aberrations in Human Lymphocytes by Chromosomal Suppression In Situ Hybridization
}

\author{
T. Cremer, S. Popp, P. Emmerich, P. Lichter, and C. Cremer \\ Institut für Humangenetik und Anthropologie, (T.C., S.P., P.E.), and Institut für Angewandte Physik I (C.C.), \\ D-6900 Heidelberg, Federal Republic of Germany; Department of Human Genetics, Yale University, School of \\ Medicine, New Haven, Connecticut 06510 (P.L.)
}

Received for publication August 14, 1989; accepted August 25, 1989

\begin{abstract}
Chromosomal in situ suppression (CISS)-hybridization of biotinylated phage DNA-library inserts from sorted human chromosomes was used to decorate chromosomes 1 and 7 specifically from pter to qter and to detect structural aberrations of these chromosomes in irradiated human peripheral lymphocytes. In addition, probe pUC1.77 was used to mark the 1q12 subregion in normal and aberrant chromosomes 1. Low LET radiation $\left({ }^{60} \mathrm{Co}-\gamma\right.$-rays; 1.17 and $\left.1.33 \mathrm{MeV}\right)$ of lymphocyte cultures was performed with various doses $(\mathrm{D}=0,2,4,8 \mathrm{~Gy}) 5 \mathrm{~h}$ after stimulation with phytohaemagglutinin. Irradiated cells were cultivated for an additional $67 \mathrm{~h}$ before Colcemid arrested metaphase spreads were obtained. Aberrations of the specifically stained chromosomes, such as deletions, dicentries, and rings, were readily scored after in
\end{abstract}

situ hybridization with either the 1q12 specific probe or DNA-library inserts. By the latter approach, translocations of the specifically stained chromosomes could also be reliably assessed. A linear increase of the percentage of specifically stained aberrant chromosomes was observed when plotted as a function of the square of the dose $D$. A particular advantage of this new approach is provided by the possibility to delineate numerical and structural chromosome aberrations directly in interphase nuclei. These results indicate that cytogenetic monitoring of ionizing radiation may be considerably facilitated by CISS-hybridization.

Key terms: Biological dosimetry, ionizing radiation, fluorescence in situ hybridization
Chromosome aberration analysis in human lymphocyte metaphase spreads has been established as a reliable tool for biological dosimetry $(22,41)$. Analyses performed with conventional cytogenetic techniques, however, are tedious and depend on skilled personnel (3,35). Another severe limitation of conventional cytogenetic analyses in biological dosimetry relates to the fact that it can only be performed in mitotic cells, i.e., in a small fraction of the whole irradiated cell population. Radiation induced chromosome damage could be much more reliably assessed if the whole cell population were amenable to analysis. For evaluation of interphase nuclei the technique of premature chromosome condensation (PCC) has been successfully used $(4,5,37)$, but cytogenetic analyses of prematurely condensed chromosomes may be too laborious for practical use in biological dosimetry. The micronucleus test has provided a simpler method for scoring damage to chromosomal material in cells at interphase which have undergone one cell division after irradiation $(42,43)$. However, the micronucleus test is indicative largely for cells with non-stable chromosome aberrations, which are rapidly eliminated during subsequent cell cycles $(6,16,27)$. For the assessment of long term biological effects of radiation damage the evaluation of stable chromosome aberrations, such as reciprocal translocations, appears to be of particular practical importance. Non-lethal chromosome exchanges have been implicated in the multistep process of malignant cell transformation (31). Recently, X-ray induced translocations have been correlated with transformation to anchorage-independent growth of human diploid fibroblasts 
(30). Unfortunately, the identification of small translocations of specific chromosomes is particularly difficult with conventional banding analyses.

Recent advances in the detection of specific chromosomal targets by non-radioactive in situ hybridization techniques may provide the potential to overcome most of the limitations of present approaches for the cytogenetic assessment of radiation damage. Pinkel et al. (38) have used fluorescence in situ hybridization to establish the frequency of interspecies translocations per cell as a function of neutron dose $(0.05-11.2 \mathrm{~Gy})$ in human-hamster hybrid cells. These translocations were readily visualized by in situ hybridization with biotinylated human genomic DNA, which specifically delineates the human chromosome parts (45). Recently, chromosomal in situ suppression (CISS)-hybridization techniques have been developed, which allow the specific staining of entire human chromosomes directly in human cell types $(32,33,39)$. Chemically modified DNA inserts from libraries established from sorted human chromosomes $(9,17,48)$ were used as a complex probe in this approach. It has been shown that numerical changes, deletions, and rearrangements of the visualized chromosomes can be readily detected by CISS-hybridization both in mitotic and interphase tumor cells (14). In addition, subregional chromosome specific probes were used for more detailed analysis of chromosome aberrations $(14,15,33)$. In this study we present a first application of this new approach to the assessment of chromosomal damage induced by irradiation with ${ }^{60} \mathrm{Cobalt}-\gamma$-rays in peripheral human lymphocytes and discuss its future potential for biological dosimetry.

\section{MATERIALS AND METHODS Cell Material}

Human lymphocytes from a healthy, male donor $(46, \mathrm{XY})$ were cultivated in vitro by using standard techniques (46). Five hours after stimulation with phytohaemagglutin (PHA) cultures were irradiated at room temperature with $0,2,4$, and 8 Gy of ${ }^{60} \mathrm{Co}$ gamma-rays ( 1.17 and $1.33 \mathrm{MeV})$. After additional $67 \mathrm{~h}$ of cultivation, Colcemid arrested metaphase spreads were obtained after hypotonic treatment $(0.075 \mathrm{M} \mathrm{KCl})$ and fixation with methanol/acetic acid $(3: 1, \mathrm{vv})$. For comparison of in situ hybridization patterns, metaphase spreads were obtained additionally from a testicular human germ cell tumor cultivated in vitro (20).

\section{CISS-Hybridization of Chromosomes 1 and 7}

Phage DNA-libraries from sorted chromosomes 1 and 7 were obtained from the American Type Culture Collection (chromosome 1:LA01NS01; chromosome 7: LA07NS01). Amplification of these libraries, isolation of human inserts, nicktranslation with bio-11-dUTP, CISS-hybridization, and detection of hybridized sequences with fluoresceine-isothyocyanate (FITC) conjugated avidin were carried out as described by Lichter et al. (32). For signal amplification the protocol of
Pinkel et al. (38) was used. Metaphase chromosomes and cell nuclei were counterstained with propidium iodide (PI) and viewed with a Zeiss photo microscope equipped with epifluorescence. Pictures were taken with Agfachrome 1000 ASA films.

\section{In Situ Hybridization With Probe pUC1.77}

Probe pUC1.77 was a generous gift from Dr. Howard Cooke. It represents a $1.77 \mathrm{~kb}$ EcoRI fragment of human satellite II/III DNA subcloned in pUC9 (7). Plasmid DNA preparation, purification, nick translation (Nicktranslation System, Bethesda Research Laboratories, cat. no. $8160 \mathrm{SB}$; Biotin-n-dUTP, Sigma, cat. no. B7645), and fluorescence in situ hybridization were performed as described $(15,19)$.

\section{RESULTS}

\section{Delineation of Structural Chromosome}

\section{Aberrations in Metaphase Spreads of Irradiated Lymphocytes by CISS-Hybridization}

Figure 1 shows results of CISS-hybridization of chromosome 7 (Fig. 1a-c) and chromosome 1 (Fig. 1d-f,h-l) in metaphase spreads of PHA-stimulated human lymphocytes using biotinylated inserts of the respective libraries from sorted chromosomes. Figure 1a shows a metaphase spread from an unirradiated control $(46, \mathrm{XY})$. Both chromosomes 7 are completely and specifically decorated from pter to qter with biotinylated chromosome 7 sequences. Their yellow color clearly contrasts with the red color of non-targeted chromosomes. It results from the superposition of green fluorescence (as derived from the detection of biotinylated sequences with fluorescein isothiocyanate [FITC] conjugated avidine) and red fluorescence (as derived from counterstaining of the whole chromosome complement with propidium iodide). Figure 1b,c shows several rearrangements (monocentric and dicentric translocations) of chromosome 7 material in metaphase spreads obtained after $\gamma$-irradiation of lymphocyte cultures. Figure $1 \mathrm{~d}-\mathrm{f}, \mathrm{h}-\mathrm{l}$ provides examples of $\gamma$-radiationinduced structural aberrations of chromosome 1, including simple translocations, insertions, dicentrics, rings, and fragments. At the time when metaphase spreads were collected many cells were in a tetraploid state showing identical twin dicentrics and other rearrangements (e.g., Fig. 1b,d-f). These duplicated aberrations confirm the reliability with which even small translocations can be detected by this approach (Fig. $1 \mathrm{~b}, \mathrm{~d})$. CISS-hybridization provided a powerful tool with which to detect the involvement of specific chromosomes in all types of aberrations (with the exception of inversions). Specific staining of chromosomal band 1q12 also allowed the detection of dicentrics (Fig. 1g), as well as deleted chromosomes 1 or rings containing this band. In contrast to the CISS-hybridization approach, however, simple translocations of chromosome 1 material with breakpoints outside the specifically labeled region could not be scored.

Table 1 summarizes the results of our quantitative 


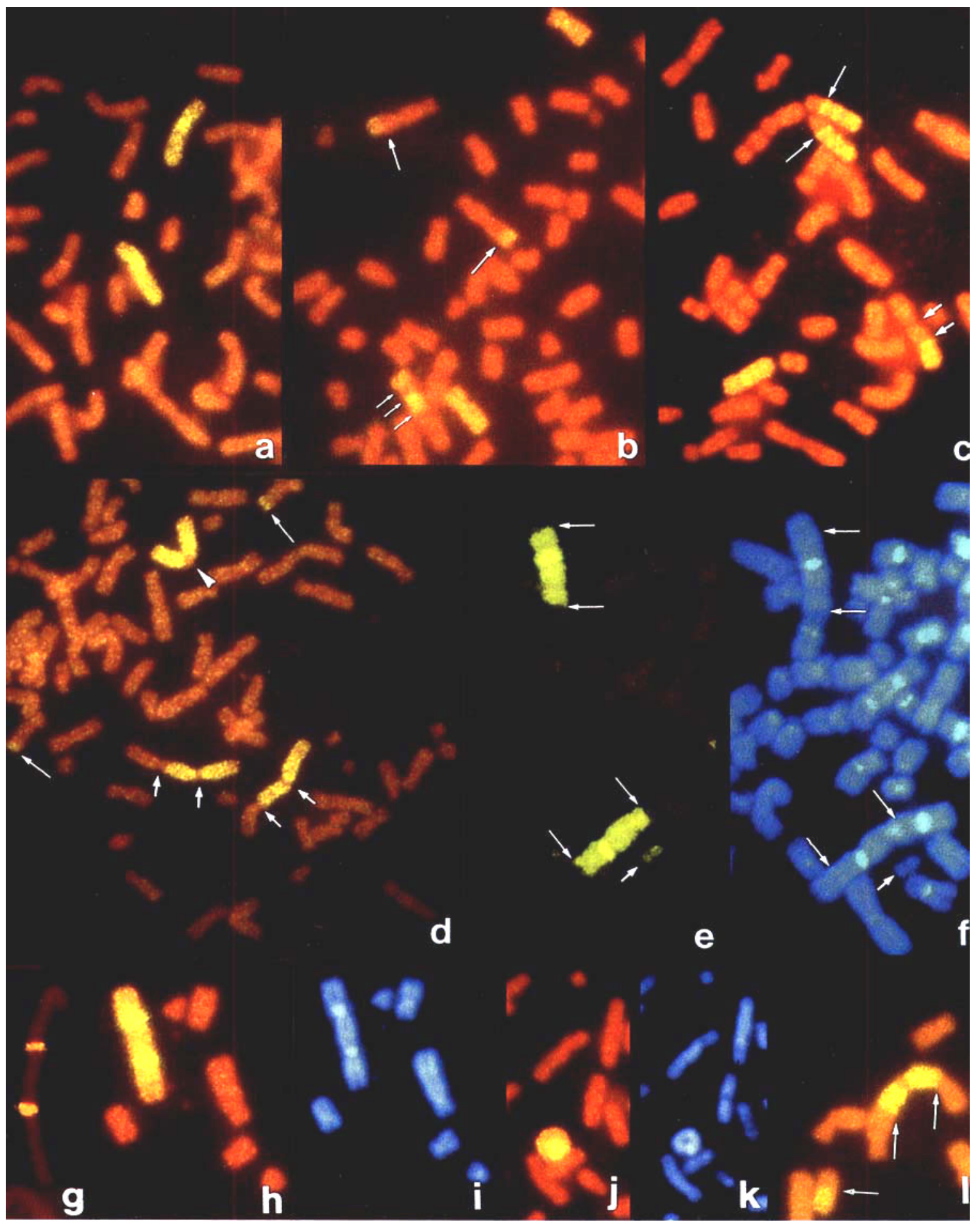

FIg. 1. 
Table 1

Detection of Radiation-Induced Chromosome Aberrations by In Situ Hybridization in Metaphase

\begin{tabular}{|c|c|c|c|c|c|c|c|}
\hline \multirow[b]{2}{*}{$\begin{array}{l}\text { Specific } \\
\text { delineation }\end{array}$} & \multirow[b]{2}{*}{$\begin{array}{l}\text { Dose } \\
(\mathrm{Gy})\end{array}$} & \multirow[b]{2}{*}{$\mathrm{N}^{\mathrm{a}}$} & \multicolumn{5}{|c|}{$\%$} \\
\hline & & & $\begin{array}{l}\text { Monocentrics } \\
\text { with translocations } \\
\text { and inserts }{ }^{b}\end{array}$ & $\begin{array}{c}\text { Deletions and } \\
\text { fragments }\end{array}$ & Dicentrics $^{c}$ & Rings & $\begin{array}{c}\text { Total } \\
\text { aberrant } \\
\text { chromosomes }\end{array}$ \\
\hline Complete & 0 & 250 & 0 & 0 & 0 & 0 & 0 \\
\hline \multirow[t]{3}{*}{$\# 1$} & 2 & 250 & 2 & 2 & 2 & 0.4 & $6.4^{*}$ \\
\hline & 4 & 250 & $6 *$ & $6.8^{* *}$ & 3.2 & 1.6 & $17.6^{*}$ \\
\hline & 8 & 350 & $38.9^{*}$ & $24.3^{*}$ & $16^{*}$ & 0.8 & $80^{*}$ \\
\hline Complete & 0 & 250 & 0 & 0 & 0 & 0 & 0 \\
\hline \multirow[t]{3}{*}{ \#7 } & 2 & 250 & 3.2 & 2.4 & 0.8 & 0 & $6.4^{*}$ \\
\hline & 4 & 250 & $14.8^{*}$ & 4.8 & 1.2 & 1.2 & $22^{;}$ \\
\hline & 8 & 350 & $35.5 *$ & $14^{*}$ & $9.4^{*}$ & 1.4 & $60.3^{*}$ \\
\hline \multirow[t]{4}{*}{$1 q 12$} & 0 & 400 & n.d. & 0 & 0 & 0 & 0 \\
\hline & 2 & 250 & n.d. & 0.8 & 0.4 & 0 & 1.2 \\
\hline & 4 & 250 & n.d. & $6^{* *}$ & 2 & 0 & $8^{* * *}$ \\
\hline & 8 & 250 & n.d. & 29.2 & $5.2^{*}$ & 1.6 & $36 \%$ \\
\hline
\end{tabular}

${ }^{a} \mathrm{~N}$, number of chromosomes examined containing hybridized material.

${ }^{b}$ n.d., not determined.

"Containing a few tricentrics observed at $8 \mathrm{~Gy}$.

*The increase over the next lower dose value is significant on the $99 \%$ confidence level.

**The increase over the value at $0 \mathrm{~Gy}$ is significant on the $99 \%$ confidence level.

assessment of aberrant metaphase chromosomes 1 and 7 in $\gamma$-irradiated lymphocyte cultures. For each dose $(0$, $2,4,8 \mathrm{~Gy}) 250-400$ specifically labeled chromosomes were scored. In addition to CISS-hybridization, DAPI and/or propidium iodide staining was used for the structural evaluation of normal and aberrant chromosomes. A linear increase of the accumulated percentage

FIG. 1. Metaphase chromosomes of peripheral human lymphocyte cultures $(46, \mathrm{XY})$ following low LET irradiation and fluorescence in situ hybridization (a: 0 Gy; c, h-k: 4 Gy; b, d-g, l: 8 Gy). a-c: CISShybridization of chromosome $7 . \mathrm{d}-\mathrm{f}, \mathrm{h}-\mathrm{l}$ : CISS-hybridization of chromosome 1. g: In situ hybridization with probe pUC1.77. Yellow-green fluorescence indicates specifically labeled chromosome material (a-e, $\mathrm{g}, \mathrm{h}, \mathrm{j}, \mathrm{l})$. Chromosomes are counterstained with propidium iodide (a-e, $\mathrm{g}, \mathrm{h}, \mathrm{j}, \mathrm{l})$ and $\mathrm{DAPI}(\mathrm{f}, \mathrm{i}, \mathrm{k})$. a: Two normal chromosomes 7 are delineated from pter to qter in a non-irradiated control. b: Two normal chromosomes 7, two small translocations (large arrows) and one chromosome with inserted chromosome 7 material (small arrows point to the breakpoint regions). c: One normal chromosome 7 and two translocations of chromosome 7 material (large arrows). Small arrows indicate centromere positions of a dicentric with a translocation. d: One normal chromosome 1 is indicated by an arrowhead. Two dicentrics with chromosome 1 material are clearly visualized (small arrows indicate centromere positions). Large arrows indicate two translocation chromosomes with small parts of chromosome 1 material. e: Two dicentric chromosomes with inserted chromosome 1 material and a specifically decorated chromosome 1 fragment (arrows as in $\mathrm{f}$ ). $\mathrm{f}$ : The same chromosomes as in e after DAPI staining. The large arrows point to the breakpoint regions where the chromosome 1 material is inserted. The small arrow points to the fragment of chromosome 1 material. $g$ : Dicentric chromosome with two $1 \mathrm{q} 12$ subregions specifically stained. h: Completely labeled dicentric chromosome 1. i: The same chromosomes as in $h$ after DAPI staining. $j$ : Ring chromosome consisting of chromosome 1 material. $\mathbf{k}$ : The same chromosomes as in $\mathrm{j}$ after counterstaining with DAPI. 1: Two translocation chromosomes containing chromosome 1 material. The long chromosome contains an insert of chromosome 1 material including the non-labeled centromeric region of chromosome 1. The arrows indicate the breakpoint regions. of the aberrant chromosomes as a function of the square of the dose $D$ was noted. These quadratic doseeffect relationships were observed with regard to the percentages of breaks, deletions, and fragments, of monocentrics with translocations, as well as of dicentrics (Fig. 2; compare Table 1). For all doses tested the increase in the yield of all types of aberrant chromosomes (Fig. 2, curve 1) was significant (99\% confidence level) over the next lower dose.

\section{Delineation of Chromosome Aberrations in Interphase Nuclei of Irradiated Human Lymphocytes by CISS-Hybridization}

Figure 3a-e shows examples of interphase nuclei with normal and abnormal staining patterns of chromosome 1 domains after CISS-hybridization with the respective library inserts. Many nuclei from irradiated samples showed a grossly disturbed staining pattern including extra domains of various sizes probably resulting from irradiation-induced mitotic non-disjunction and translocation events (Fig. 3b,c). Other nuclei showed both an increased size and increased numbers of hybridized chromosome domains and were considered as polyploid (Fig. 3d). Similar interphase staining patterns were obtained after CISS-hybridization with chromosome 7 library inserts (not shown). The potential of interphase cytogenetics as compared to the evaluation of metaphase spreads in detecting cells with extra copies and translocations of specific chromosomes is further demonstrated by Figure $3 \mathrm{e}$ and f. Figure $3 \mathrm{f}$ shows a metaphase spread from a testicular human germ cell tumor cultivated in vitro (20). Besides two apparently normal chromosomes 1 (as revealed by additional banding studies, results not shown), a third chromosome 1 was deleted and three translocations of 


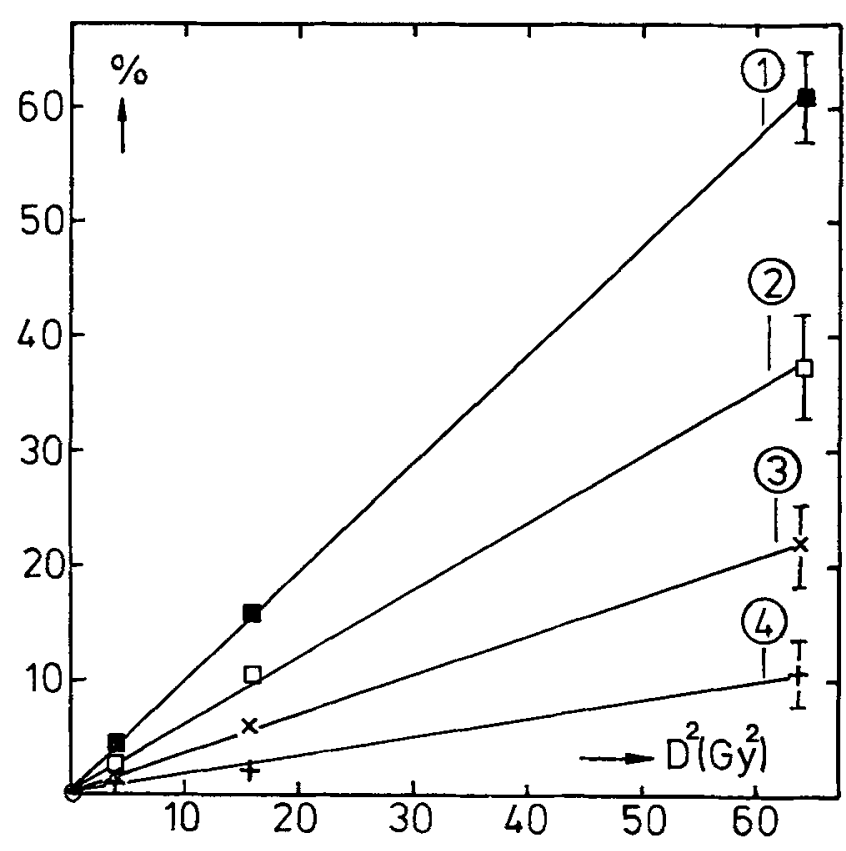

FIG. 2. Dose-effect relationships for ${ }^{60} \mathrm{C} 0-\gamma$-induced aberrations of lymphocyte metaphase chromosomes as detected by fluorescence hybridization. Abscissa: Square $\left(\mathrm{D}^{2}\right)$ of the dose $\mathrm{D}$, given in $\mathrm{Gy}^{2}$. Ordinate: Accumulated percentages $(\mathrm{Y})$ of: $(\boldsymbol{\square})$ all types of aberrant chromosomes (\#1 plus \#7 CISS-delineations plus 1q12 labeling); ( $\square$ ) monocentrics with translocations and inserts (\#1 plus \#7 delineations); ( $\mathrm{x}$ ) deletions and fragments (\#1 plus \# 7 delineations plus $1 \mathrm{q} 12$ labeling); $(+)$ dicentrics (\#1 plus \#7 delineations plus 1q12 labeling). The bars at $\mathrm{D}^{2}=64 \mathrm{~Gy}^{2}$ ( $8 \mathrm{~Gy}$ ) indicate the $99 \%$ confidence intervals (not shown for the other doses). For the percentages $\mathrm{Y}$ obtained for $\mathrm{D}^{2}$ $=0,4,16,64 \mathrm{~Gy}^{2}$, linear regression curves $\left(\mathrm{Y}=\mathrm{a}+\mathrm{bD}^{2}\right)$ and linear coefficients ( $r$ ) of correlation were calculated: curve 1: aberrant chromosomes (all types. $\mathbf{D}): \mathrm{Y}=0.51+0.95 \mathrm{D}^{2}(\mathrm{r}=1.000)$; curve 2 : monocentrics with translocations and inserts $(\square): Y=0.43+0.58 D^{2}$ $(\mathrm{r}=0.9995)$; curve 3 : deletions and fragments $(\mathrm{x}): \mathrm{Y}=0.27+0.34 \mathrm{D}^{2}$ $(\mathrm{r}=0.9998)$; curve 4 : dicentrics $(+): \mathrm{Y}=0.004+0.16 \mathrm{D}^{2}(\mathrm{r}=$ $0.9969)$.

chromosome 1 material were detected. The number and size of interphase domains seen in nuclei with appropriate domain separation (Fig. 3e) were in complete agreement with the analysis of the corresponding metaphase spreads (20). Similar results were obtained for other tumor lines (14).

Figure 4 presents data for the quantitative evaluation of nuclei in irradiated lymphocyte cultures. For this, classification of nuclei was performed according to the following criteria: Nuclei with one or two distinct domains were counted as normal (Fig. 3a), while nuclei showing no hybridization signals were excluded from further consideration. Nuclei with more than two signals as exemplified in Figure $3 \mathrm{~b}-\mathrm{d}$ were considered abnormal.

In agreement with the evaluation of metaphase spreads, the interphase dose-response curves suggest a quadratic dependence on dose. About 5\% of control nuclei also exhibited staining patterns which were arbitrarily classified as abnormal by these criteria. This contrasts with the evaluation of metaphase spreads where no structural chromosome aberrations were seen in non-irradiated cells. The reason for this discrepancy is presently unclear but is likely to reflect technical shortcomings rather than indicating actual chromosomal aberrations in a subset of non-irradiated interphase cells which could not be evaluated at metaphase (see Discussion).

\section{DISCUSSION}

Staining of entire individual human chromosomes or parts thereof by using fluorescence in situ hybridization of probes with various complexity has provided a new and simple means for the rapid detection of numerical and structural aberrations in both metaphase and interphase cells. Here we have applied CISS-hybridization to the detection of chromosome aberrations in ${ }^{60} \mathrm{Co}-\gamma$-irradiated human lymphocytes by using libraries from sorted chromosomes 1 and 7 as complex probes. In addition, probe pUC1.77 (7) was used to delineate the 1q12 band in normal and aberrant chromosomes 1 . In agreement with other investigations (35), a linear increase of dicentrics was observed with the square of the dose $\mathrm{D}$ within the dose range used. Our data demonstrate the usefulness of CISS-hybridization as a method for the rapid assessment of a broad spectrum of chromosome aberrations in metaphase spreads of irradiated cells. This technique allows the rapid scoring of both unstable and stable chromosome aberrations after radiation exposure. Specific chromosomes can be easily screened for their participation in aberration events even in metaphase spreads of poor quality (14). The easiness with which stable translocations can be detected $(14,20$; A. Jauch and T. Cremer, unpublished data) should make it possible to screen for radiation-induced damage even in cells which have undergone many successive mitoses after a radiation event or to screen for cumulative effects of repeated radiation exposures. Aberration scoring of specific chromosome bands by CISS-hybridization with appropriate chromosome band specific DNA-probes or probe sets (33) should provide a possibility for the rapid testing of sice-specific chromosomal rearrangements in irradiated human diploid cells. Such specific rearrangements nay be involved in radiation-induced transformation events $(28-30)$. For the immediate purposes of biological dosimetry, however, limitation of aberration detection to single chromosomes is disadvantageous in cases where the total yield of aberrations induced in an irradiated cell population is small. The advance of multi in situ hybridization and multicolor detection protocols (36) in combination with fluorescence digital image microscopy (2) is likely to overcome this limitation soon (D.C. Ward, personal communication).

The possibility to detect numerical and structural aberrations directly in interphase nuclei opens a new avenue for biological dosimetry. Diagnostic interphase cytogenetics is still in its infancy $(13,38,39,44)$ but has 

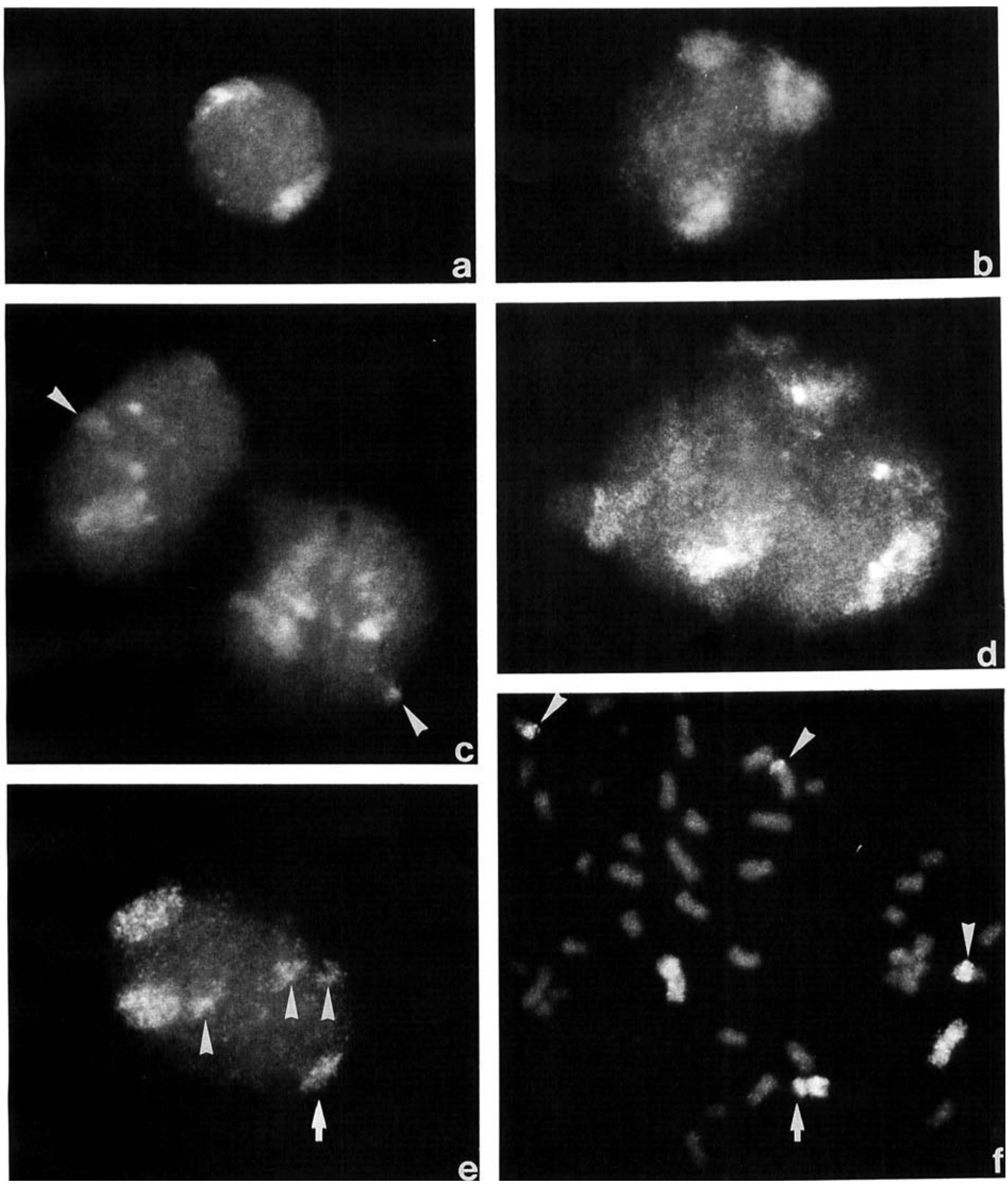

FIG. 3. Visualization of normal and aberrant chromosome 1 domains in human interphase nuclei. a: Nucleus from a non-irradiated lymphocyte culture after CISS-hybridization of two chromosome 1 domains. The nucleus was counterstained with PI. b-d: Lymphocyte nuclei with aberrant chromosome 1 pattern after irradiation with ${ }^{60} \mathrm{Co}-\gamma$-rays ( $8 \mathrm{~Gy}$ ). b: Nucleus shows three large chromosome 1 domains. c: Two nuclei with small extra domains (arrowheads) suggesting rearranged chromosomes. $d$ : Large nucleus with at least four do-

mains indicating polyploidization. e-f: Nucleus (e) and corresponding metaphase (f) from the testicular germ cell tumor line Germa 2 after CISS-hybridization. Two normal chromosomes 1 are shown as two large domains in the nucleus. The arrows point to a smaller nuclear domain (e) and a metaphase chromosome (f) indicating a deleted chromosome 1. In addition, three translocations (arrowheads) are visualized. 


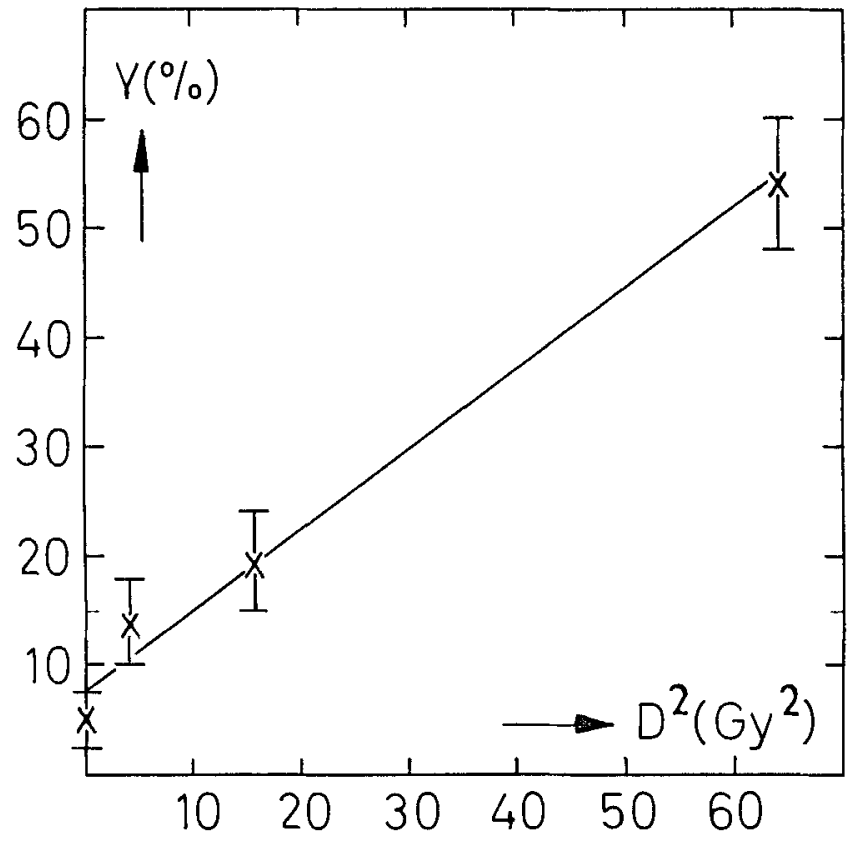

Fic 4. Dose-effect relationship for ${ }^{60} \mathrm{Co}-\gamma$-ray-induced aberrations of chromosomes 1 and 7 in lymphocyte interphase nuclei. Abscissa: square $\left(\mathrm{D}^{2}\right)$ of the dose $\mathrm{D}$, given in $\mathrm{Gy}^{2}$. Ordinate: percentage $(\mathrm{Y})=$ number of nuclei with aberrant chromosome 1 plus number of nucle with aberrant chromosome 7 pattern (see Fig. 3b-d) divided by the total number $(n)$ of evaluated nuclei. $\times 100$. For each dose value, $n=$ 500 nuclei were evaluated. The bars indicate the $99 \%$ confidence ranges. From the experimental data for $\mathrm{D}^{2}=0,4,16,64 \mathrm{~Gy}^{2}$, a linear regression curve was calculated $\left(Y=7.67+0.72 \mathrm{D}^{2}\right.$; linear coefficient of correlation: $r=0.9936$ )

already proven to be a useful adjunct in tumor cytogenetics $(14,15,26)$. As compared to banded metaphase spreads, however, the reliability with which normal and abnormal chromosomes can be counted in interphase nuclei by in situ hybridization of specific chromosomal targets is still limited for various reasons $(14,15,32)$. Insufficient penetration of DNA-probes may result in too low counts. On the other hand, cross hybridization of DNA-probes to other than the targeted chromosomal sites may yield too high numbers. In addition, inhomogeneous hybridization of more extended individual chromosome domains may wrongly suggest two domains. It is expected that scoring of false positives due to technical insufficiencies of present protocols can be reduced by multicolor labeling of adjacent blocks of chromatin in individual chromosomes of interest. DNA-probes from phage DNA-, cosmid-, or YAC-libraries useful for such purposes are presently being developed in large numbers during the ongoing efforts to physically map the human genome. CISShybridization makes it possible to use these clones without the need to isolate single-copy sequences (34). We expect that interphase cytogenetics will eventually become a tool for chromosome aberration detection as reliable and versatile as present techniques of metaphase spread evaluation.
The interphase cytogenetics approach can be applied to paraffin embedded tissue sections (21). Thus it should become possible in the future to test solid tissue specimens (e.g., derived by biopsies after partial body exposures) or cells from body fluids for radiation-induced chromosome damage without the necessity of prior in vitro cultivation. A combination of PCC (see Introduction) and CISS-hybridization techniques should provide an ideal tool for the detailed investigation of chromosome damage and repair in interphase nuclei.

Digitall image analysis of the specifically stained metaphase and interphase chromosomes $(10,11,19,25)$ may be applied with appropriate threshold setting to outline automatically the decorated chromatin (including translocations) even in cases of non-optimal hybridization with considerable background on nontargeted chromosomes (15). After conventional staining procedures of chromosomes, the $2 \mathrm{D}$-image analysis procedures used for the automatic detection of chromosome aberrations (40) require the segmenting of all individual chromosomes of a metaphase spread. In CISS-hybridization experiments, problems due to chromosomal overlap are greatly reduced, since the specifically decorated chromosome can be easily distinguished from overlapping non-targeted chromosomes (14). Since the chromosome of origin is known for all specifically decorated chromosome fragments, these specifically decorated normal chromosomes may provide parameters to discriminate against free or translocated fragments thereof simply by means of their decreased size and/or total fluorescence intensity. In case of translocation chromosomes, the difference in fluorescence between the yellow-green (PI + FITC) fluorescence of the specifically decorated part and the red fluorescence of the PI-counterstained, non-targeted part adds another parameter. This difference may easily be exploited in the automated image analysis by using appropriate CCD-cameras (M. Kraft and C. Cremer, unpublished data). Slit-scan flow cytometry $(10,11,23,24)$ following fluorescence in situ hybridization of individual metaphase chromosomes in suspension $(12,18)$ may be considered as another promising approach to fast automatic scoring of chromosome aberrations $(10,25)$. Finally, it should be noted that the approach described should also be suited for studies of chromosome damaging chemical agents including the synergistic effects between DNA-repair inhibitors and irradiation damage $(1,8,47)$.

\section{ACKNOWLEDGMENTS}

T.C. is the recipient of a Heisenberg-Stipendium and P.L. of a Forschungs-Stipendium, both from the Deutsche Forschungsgemeinschaft. P.E. was supported by a Biostipendium from the Bundesministerium für Forschung und Technologie (BMFT). We thank the German Cancer Research Center (DKFZ), Heidelberg, for the possibility to use a ${ }^{60} \mathrm{Co}-\gamma-\mathrm{ray}$ source, Eiethesda Research Laboratories for support to cover the cost of the color figure, J. Hollatz and A. Wiegenstein for excellent photographic work. 


\section{LITERATURE CITED}

1. Andersson $\mathrm{HC}$, Kihlman BA: Effects of $\mathrm{G}_{2}$ treatments with inhibitors of DNA synthesis and repair on chromosome damage induced by X-rays and chemical clastogens in root tips of Vicia faba. Mutat Res 181:173-185, 1987.

2. Arndt-Jovin DJ, Robert-Nicoud J, Kaufman SJ, Jovin TM: Fluorescence digital imaging microscopy in cell biology. Science 230(4723):247-256, 1985

3. Bauchinger M: Cytogenetic effects in human lymphocytes as a dosimetry system. In: Biological Dosimetry, Eisert. WG, Mendelsohn ML (eds). Springer-Verlag, Berlin, 1984, pp 15-24.

4. Bedford JS, Goodhead DT: Breakage of human interphase chromosomes by alpha particles and X-rays. Int $\mathrm{J}$ Radiat Biol 55(2): 211-216, 1989

5. Bertsche U, Zimmermann U: Analysis of X-ray induced aberrations in mammalian chromosomes by electrofusion induced premature chromosome condensation. Radiat Environ Biophys 27: 201-212, 1988

6. Carrano AV: Chromosome aberrations and radiation induced cell death. I. Transmission and survival parameters of aberrations. Mutat Res 17:341-353, 1973 .

7. Cooke HJ, Hindley J: Cloning of human satellite III DNA: Different components are on different chromosomes. Nucleic Acids Res 6:3177-3197, 1979.

8. Cremer C, Cremer T: Induction of chromosome shattering by ultraviolet light and caffeine: The influence of different distributions of photolesions. Mutat Res 163:33-40, 1986.

9. Cremer C, Rappold G, Gray JW, Müller CA, Ropers HH: Preparative dual beam sorting of the human $\mathrm{Y}$ chromosome and in situ hybridization of cloned DNA probes. Cytometry 5:572-579, 1984

10. Cremer C, Hausmann M, Diaz E, Hetzel J, Aten JA, Cremer T: Chromosome aberration detection with hybridized DNA probes: Digital image analysis and slit scan flow cytometry. In: Automation of Cytogenetics, Lundsteen C, Piper J (eds). Springer-Verlag, Berlin, 1989

11. Cremer C, Hausmann M, Zuse P, Aten JA, Barths J, Bühring HJ: Flow cytometry of chromosomes: Principles and applications in medicine and molecular biology. Optik 82:9-18, 1989.

12. Cremer C, Dölle J, Hausmann M, Bier FF: Laser cytometry: Applications in flow cytogenetics. Phys Chem 93:327-335, 1989.

13. Cremer T, Landegent JE, Brückner H, Scholl HP, Schardin M, Hager HD, Devilee P, Pearson PL, van der Ploeg M: Detection of chromosome aberrations in the human interphase nucleus by visualization of specific target DNAs with radioactive and non-radioactive in situ hybridization techniques: Diagnosis of trisomy 18 with probe L1.84. Hum Genet 74:346-352, 1986

14. Cremer T, Lichter P, Borden J, Ward DC, Manuelidis L: Detection of chromosome aberrations in metaphase and interphase tumor cells by in situ hybridization using chromosome-specific library probes. Hum Genet 80:235-246, 1988.

15. Cremer T, Tesin D, Hopman AHN, Manuelidis L: Rapid interphase and metaphase assessment of specific chromosomal changes in neuroectodermal tumor cells by in situ hybridization with chemically modified DNA probes. Exp Cell Res 176:199$220,1988$.

16. Das BC, Sharma T: The fate of X-ray-induced chromosome aberrations in blood lymphocyte culture. Mutat Res 176:93-104, 1987.

17. Davies K, Young B, Elles R, Hill M, Williamson R: Cloning of a representative genomic library of the human $\mathrm{X}$ chromosome after sorting by flow cytometry. Nature 293:374-376, 1981.

18. Dudin G, Cremer T, Schardin M. Hausmann M, Bier F, Cremer C: A method for nucleic acid hybridization for isolated chromosomes in suspension. Hum Genet 76:290-292, 1987.

19. Emmerich P, Loos P, Jauch A, Hopman AHN, Wiegant J, Higgins M. White BN, van der Ploeg M, Cremer C, Cremer T: Double in situ hybridization in combination with digitized image analysis: A new approach to study interphase chromosome topography. Exp Cell Res 181:126-140, 1989.

20. Emmerich P: Interphasezytogenetische Untersuchungen an Gewebeschnitten und In Vitro Kuitivierten Normalen Menschli- chen Zellen Sowie an Hodenkeimzelltumoren. Thesis, submitted to the Faculty of Theoretical Medicine, Heidelberg, 1989.

21. Emmerich P, Jauch A, Hofmann MC, Cremer T, Walt H: Interphase cytogenetics in paraffin embedded sections from human testicular tumor xenografts and in corresponding cultured cells. Lab Invest 61(2):235-242, 1989

22. Evans HJ, Buckton KE, Hamilton GE, Carothers A: Radiationinduced chromosome aberrations in nuclear-dockyard workers. Nature 277:531-534, 1979 .

23. Gray JW, Peters D, Merrill JT, Martin R, van Dilla MA: Slit sean flow cytometry of mammalian chromosomes. J Histochem Cytochem 27:441-444, 1979.

24. Gray JW, Lucas J, Yu LC, Langlois R: Flow cytometric detection of aberrant chromosomes. In: Biological Dosimetry, Eisert W, Mendelsohn M (eds). Springer-Verlag, Berlin, 1984, pp 25-35.

25. Hausmann M, Dudin G, Aten JA, Bühring HJ, Diaz E, Dölle J, Bier F, Cremer $\mathrm{C}$ : Flow cytometric detection of isolated chromosomes following fluorescence hybridization. Biomed Optics (in press).

26. Hopman AHN, Ramaekers FCS, Raap AK, Beck JLM, Devilee P, van der Ploeg M, Vooijs GP: In situ hybridization as a tool to study numerical chromosome aberrations in solid bladder tumors. Histochemistry 89:307-312, 1988.

27. Kano Y, Little JB: Persistence of X-ray-induced chromosomal rearrangements in long-term cultures of human diploid fibroblasts. Cancer Res 44:3706-3711, 1984.

28. Kano Y, Little JB: Mechanisms of human cell neoplastic transformation: X-ray-induced abnormal clone formation in long-term cultures of human diploid fibroblasts. Cancer Res 45:2550-2555, 1985.

29. Kano Y, Little JB: Site-specific chromosomal rearrangements induced in human diploid cells by X-irradiation. Cytogenet Cell Genet 41:22-29, 1986.

30. Kano Y, Grosovsky AJ, Little JB: Interrelationships among Xray-induced anchorage independence mutagenesis and chromosomal rearrangements in human diploid fibroblasts. Int $\mathrm{J}$ Cancer 40:64-68, 1987

31. Klein G: The role of gene dosage and genetic transposition in carcinogenesis. Nature 294:313-318, 1981.

32. Lichter P, Cremer T, Borden J, Manuelidis L, Ward DC: Delineation of individual human chromosomes in metaphase and interphase cells by in situ suppression hybridization using recom. binant DNA libraries. Hum Genet 80:224-234, 1988.

33. Lichter P, Cremer T, Chang Tang CJ, Watkins PC, Manuelidis L, Ward DC: Rapid detection of chromosome 21 aberrations by in situ hybridization. Proc Natl Acad Sci USA 85:9664-9668, 1988.

34. Lichter P, Chang Tang CJ, Call K, Lewis K, Evans GA, Housman D, Ward DC: High resolution mapping of human chromosome 11 by in situ hybridization with cosmid clones. Science (in press).

35. Lloyd DC: An overview of radiation dosimetry by conventional cytogenetic methods. In: Biological Dosimetry, Eisert WG, Mendelsohn ML (eds). Springer-Verlag, Berlin, 1984, pp 3-14.

36. Nederlof PM, Robinson D, Abuknesha R, Wiegant J, Hopman AHN, Tanke HJ, Raap AK: Three-color fluorescence in situ hybridization for the simultaneous detection of multiple nucleic acid sequences. Cytometry 10:20-27. 1989

37. Pantelias GE, Maillie HD: The use of peripheral blood mononuclear cell prematurely condensed chromosomes for biological dosimetry. Radiat Res 99:140-150, 1984.

38. Pinkel D, Straume T, Gray JW: Cytogenetic analysis using quantitative, high-sensitivity, fluorescence hybridization. Proc Natl Acad Sci USA 83:2934-2938, 1986.

39. Pinkel D, Landegent J, Collins C, Fuscoe J, Segraves R, Lucas J, Gray JW: Fluorescence in situ hybridization with human chromosome-specific libraries: Detection of trisomy 21 and translocations of chromosome 4. Proc Natl Acad Sci USA 85:9138-9142, 1988.

40. Piper J, Lundsteen C; Human chromosome analysis by machine. Trends Genet 3:309-313, 1987

41. Pohl-Rüling J, Fischer $P$, Haas $O$, Obe $G$, Natarajan A'T, van Buul PPW, Buckton KE, Bianchi NO, Larramendy M, Kucerova M, Polikova Z, Leonard A, Fabry L, Palitti F, Sharma T, Binder 
W, Mukherjee RN, Mukherjee U: Effect of low-dose acute X-irradiation on the frequencies of chromosomal aberrations in human peripheral lymphocytes in vitro. Mutat Res 110:71-82, 1983.

42. Prosser JS, Moquet JE, Lloyd DC, Edwards AA: Radiation induction of micronuclei in human lymphocytes. Mutat Res 199:37-45 1988.

43. Ramalho A, Sunjevaric I, Natarajan AT: Use of the frequencies of micronuclei as quantitative indicators of X-ray-induced chromosomal aberrations in human peripheral blood lymphocytes: Comparison of two methods. Mutat Res 207:141-146, 1988.

44. Rappold GA, Cremer T, Hager HD, Davies KE, Müller CR, Yang T: Sex chromosome positions in human interphase nuclei as studied by in situ hybridization with chromosome specific DNA probes. Hum Genet 67:317-325, 1984.

45. Schardin M, Cremer T, Hager HD, Lang M: Specific staining of human chromosomes in Chinese hamster $\times$ man hybrid cell lines demonstrates interphase chromosome territories. Hum Genet 71: 281-28i, 1985.

46. Schwarzacher HG: Präparation von Mitose-Chromosomen. In: Methoden in der Medizinischen Cytogenetik, Schwarzacher HG, Wolf U (eds). Springer-Verlag, Berlin, 1970, pp 55-66.

47. Sobels FH: Studies in comparative chemical mutagenesis. Environ Mutagen 7:759-773, 1985.

48. Van Dilla MA, Deaven LL, Albright KL, Allen NA, Aubuchon MR, Bartholdi MF, Brown NC, Campbell EW, Carrano AV, Clark LM, Cram LS, Crawford BD, Fuscoe JC, Gray JW, Hildebrand CE, Jackson PJ, Jett JH, Longmire JL, Lozes CR, Luedemann ML, Martin JC, McNinch JS, Meincke LJ, Mendelsohn ML, Meyne J, Moyzis RK, Munk AC, Perlman J, Peters DC, Silva AJ, Trask B.J: Human chromosome-specific DNA libraries: Construction and availability. Biotechnology 4:537-552, 1986. 